DOI: https://dx.doi.org/10.26808/rs.ca.i8v2.10

\title{
E RTO: Modulation and Enhancement
}

\author{
${ }^{1}$ Pranavi Gupta , ${ }^{2}$ Anisha Bijlani ${ }^{3}$, Akanksha Singh and ${ }^{4}$ A.K Srivastava
}

\section{Abstract:}

In the Internet era, being a citizen of developing country its quite important to digitalize our nation by taking small steps in our day to day work and make them electronically accessible. So in this direction we shaped our RTO (Regional Transport Office) system online.

Keywords: RFID, ERTO, RTO, Vehicle authentication.

\section{Introduction:}

The RTO vehicle registration system has been developed to override the problems prevailing in the practicing manual system. The software is supported to eliminate and in some case reduce the hardship faced by the existing system. It is also designed to carry out all the operations in a smooth manner.

The purpose of RTO system is to automate the existing manual system with the help of computerized equipment by fulfilling the requirement so that their information is secure and can be easily accessed and managed. This lead to the error free, secure, well grounded and fast management system. It will provide the user with many facilities like registration, insurance, tracking of vehicles. It can maintain the computerized records without having the redundant records. This will result in better utilization of the resource. It will describe how to manage for good performance and better service for better clients It may happen that at times the Driver forgets to carry his driving license with him. This paper is put forward to solve such problems in such a situation if he is registered with our website then he can download his driving license immediately from our website and in this way he is not always bound to carry the hard copy of his driving license with him. As in this website the data is stored regarding the driver and their vehicle by the Database Administrator.

\section{Objective:}

The main objective of this project on RTO vehicle registration system is to manage the details of vehicle registration, license, and vehicle type and so on. This project is totally based on administrative end so only he is liable to give authority to end user. The motive of this website is to reduce the paper work as much as possible and to work manually.

This website will provide the following features:

- To create a web page which can be used in place of old system.

- It keeps all the information of registration, vehicle type etc.

- To increase the efficiency of managing

- Any kind of modification is easy and very efficient as compared to do manually

- To provide effortless and organized way for completion of RTO work.

- To save the time and energy. 
DOI: https://dx.doi.org/10.26808/rs.ca.i8v2.10

\section{Related Work:}

In today's scenario people are just so busy with their work and just going to the RTO office for issuing the DL increases their work load somehow. This website will reduce this and going just for the driving test they can get their license which will ultimately reduce their extra time.

In the existing system the user has to spend a lot of time and money in making of driving license. At every step he has to spend some money so that his work can be done quickly. In doing this work manually, it's quite difficult to manage all the documents. At times the documents are lost and then the client has to suffer the loss.

Even sometimes if the driver forgets his Driving License then he has to send someone back to home to get it, in this a lot of time is wasted.

\section{Proposed System:}

The proposed system is an enhanced web application for RTO Management System and use the RFID(Radio Frequency Identification) system for the vehicle authentication. In this we are adding the feature of tracking the vehicle in the case of emergency. This will also be accurate in terms of authority as the administration will be responsible to verify all the data. First the user need to register himself and then with the details the person can login and can have access their information. Then the user can apply for the license or whatever the person needs to.

This website uses ASP.Net at server side. To build the ASP.Net WebPages it uses Visual Studio 2012 and SQL Server Management Studio for the database management.

\section{Module:}

- Administrator: It is the one who has the ultimate power. He has the power. He has the power to verify the data and all the processing of data.

- Authorized User: The user will be authorized by the administrator and authorized person will be like insurance agency, the officers which are working there and the police department.

- User: He is the one who will get the advantage of this facility. This system is providing some salient features:

- Registration through online.

- Fancy number selection.

- Issue of the information of driving license.

- It will be beneficial for tracking vehicles.

- Provide mail alerts for the expiry of license.

\section{System Overview:}

This system consists of admin, users and the agencies like police, insurance. The administrator will have the power to approve and verify the registration. This will also provide the facility of selection of fancy no. and the mail alerts for the expiry of the license and will handle all the issues related to license. It is divided into 3 main categories.

\section{a) RTO administrator:}

This part of module consists the details of the user information and the vehicle information and all the details of the registration in (fig. 1). 
DOI: https://dx.doi.org/10.26808/rs.ca.i8v2.10 International Journal of Computer Application (2250-1797)

Issue 8 Volume 2, March-April 2018

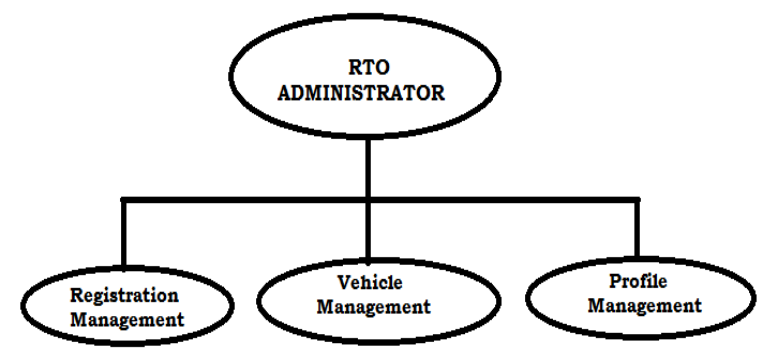

Figure 1:

\section{b) Traffic Police Architecture:}

This part of the modulehelps in providing information to the traffic police, so that they can take appropriate action in their respective cases related to the vehicles. It includes details of the vehicles through which challan can be generated. The Civil Police is also involved in this as it is responsible for updating the traffic police regarding the criminal offences done using the vehicles.(fig. 2)

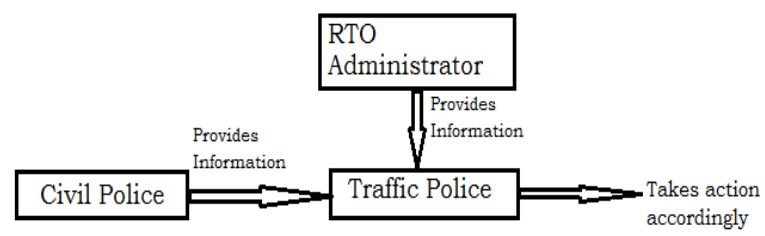

Figure 2:

c) Civil Police Portal:

The Civil Police plays a very important role In accurately and immediately identifying the vehicle which is used for the criminal offence or the vehicles which had been stolen by the criminals. It is very important that the data should be accurately updated in the database, any inaccuracy regarding data updation may lead to many serious problems and may generate problems for the common man.

\section{Working:}

Step 1: Start.

Step 2: Home page of the website will be displayed.

Step 3: Users have to register themselves toget the benefits of the website and it also helps them to get authenticated.

Step 4: If the person is authentic then he can use any of the three modules according o their need:

(i) RTO administrator, manages database (insertion and deletion of data)

(ii) Traffic Police, Input fields will be provided to enter the data.

(iii) Civil Police, Updates the data according to the cases registered.

Step 5 (i) RTO Admin: He is responsible for managing the database.

(ii) Traffic Police: It queries the given input, if it is true then the data is fetched, if not then error status will be shown.

(iii)Civil Police: Criminal offences will be updated in the database. 
DOI: https://dx.doi.org/10.26808/rs.ca.i8v2.10 International Journal of Computer Application (2250-1797)

Issue 8 Volume 2, March-April 2018

\section{Conclusion:}

It is concluded that "Verification of License is linked through Aadhaar Card". This website will provide the administrator to do all work in a very efficient manner which saves the lot of time and energy. This will also help the traffic policeman who can easily see that how many times a particular person has been penalized and moreover the people will not be dependent on carrying the driving license and the expiry of license will also be informed through mail to the people.

\section{Future Work:}

The website can be enhanced by adding the facility to track the vehicles in case of any kind of emergency. We are also providing the customers with the facility to download the driving license directly from the website. It would play an important role in digitization of the nation, which is one of the major need of the time.

\section{References:}

(1) AlpanaGopi, LittyRajan, Divya P R, Surya Rajan, "ERTO Management System and Vehicle Authentication Using RFID", International Research Journal of Engineering and Technology(IRJET) Vol-4, Issue 05,May 2017.

(2) AmrutaG.Bakale, SpoortiS.Awate, Megha G.K, Pratibha S.H, Praveen KumarN.Hadapad, "Cross Verification of Vehicle and Driver for RTO”, International Journal of Emerging Technology in Computer Science \& Electronics(IJETCSE) Vol-14, Issue 2,April 2015.

(3) Narayan S. Rau,'Issues in the path toward an RTO and Standard Markets", IEEE Transactions on Power Systems, VOL 18. NO. 2MAY 2003.

(4) Wan-MiChen,Yu-Cheng Chen, "Web Design and Implementation for remote control " in Intelligent Control and Automation(WCICA),2012 pp. 920-924

(5) Xiaosheng Yu, Yichang, China Cai," Design and Implementation of the Website Based in PHP \& MYSQL", in

E-Product E-Service and E-Entertainment(ICEEE),201,pp 1-4

(6) Norul Huda Yusof,Rosilah Hassan," Flash Notes and Easy Electronic Software(EES). New technique to Improve Digital Logic Design Learning”, in International Conference on Electrical Engineering and Informatics ,2011 